\title{
A FORMA DO ENSAIO E SUAS DIMENSÕES
}

\author{
Alfonso Berardinelli
}

O ensaísmo não é um gênero literário menor. Apesar disso, paradoxalmente, sua existência foi ofuscada pela sua própria difusão, pela versatilidade e imediatez de seu uso prático. A escrita com a qual comunicamos pensamentos, juízos, reflexões, interpretações pode se apresentar como um tipo de escrita direta, mas ao mesmo tempo sofisticada e indócil ou, ao contrário, flexível e maleável. Os grandes ensaístas foram com frequência extraordinariamente respeitados e agressivos, até mesmo invasivos. Podem ter chegado a definir e orientar épocas literárias inteiras. Mas, por outro lado, enquanto escritores criativos, agiram com discrição, como se a linguagem do pensamento crítico e da interpretação não exigisse nenhuma inventividade construtiva e estilística, alguma imaginação. De todo modo é verdade que mesmo os maiores ensaístas "criaram" e "inventaram" literariamente sem construir um mundo alternativo ao mundo real, antes dialogando com o contexto comunicativo e social de seu tempo. De Montaigne a Francisco De Sanctis, de Kierkegaard a Orwell, de Simone Weil a Gramsci, observou-se que

1 Este texto foi originalmente publicado em Il saggio. Forme e funzioni di un genere letterario. A cura di Giulia Cantarutti, Luisa Avellini e Silvia Albertazzi. Bologna: Il Mulino, 2007, p.35-44. Tradução de Maria Betânia Amoroso. 
o ensaísta pode se exprimir alternadamente de maneira idiossincrática ou anárquica, ou tecendo estratégias intelectuais inspiradas por uma "missão" pública, pela responsabilidade pedagógica e civil. O ensaio é acima de tudo o gênero literário do pensamento crítico e antidogmático e por isso exerceu uma função essencial no desenvolvimento da cultura ocidental. Por trás de sua forma pode-se ler o crescimento histórico do indivíduo moderno, mas também das discussões públicas e da razão crítica aplicada a temas de interesse coletivo.

\section{II}

O ensaio, como todos sabemos, é tentativa, prova, experimento. E isto nos revela de imediato o espírito de pesquisa arriscada e caracteristicamente pessoal do gênero. Tardiamente - talvez tarde demais - um pouco antes dos quarenta anos, percebi que para qualquer um que escreva é absolutamente necessário compreender qual é seu próprio gênero literário. Quem erra o gênero literário (o que hoje, acredito, acontece com mais frequência do que no passado) comete erro sobre erro e desperdiça as próprias energias. Depois de ter escrito poesia, de tê-la estudado intensamente, depois de ter me apaixonado pela crítica literária, por suas teorias, por seus métodos e pela sua função política, compreendi que separar o artístico do intelectual não era exatamente o meu caso. Não era poeta; ao invés de versos e metáforas, tendia a conceber aforismos e jogos dialéticos, estranhas interpretações para uso pessoal e microfilosofias não profissionais. Por outro lado, como crítico literário, eu era um tanto relutante e renitente. Não queria ser um especialista. Entendia cada vez menos o que poderia significar, em crítica literária, ser "científico". Enfim, eu suspeitava há tempos que o exercício da crítica, fora da pesquisa e do ensino acadêmico, estivesse perdendo suas legitimações tradicionais. A crítica literária, na verdade, não agradava. Não se entendia mais o que fosse. Ninguém a queria. As revistas literárias estavam em crise. Os jornais pediam resenhas de poucas linhas. A universidade pedia estudos setoriais. A poesia me parecia então um gênero literário em franco declínio: acabara o tempo dos poetasintelectuais, da poesia nutrida pelo pensamento e pela autoconsciência histórica. Mesmo tendo deixado de ser obscura e conscientemente antisocial, a poesia não possuía mais um verdadeiro público de leitores.

Os poetas de minha predileção haviam sido, a seu modo, modernos críticos da cultura. Entretanto, a grande tradição que ia de Leopardi a Montale e Pasolini, de Baudelaire a Valéry, Eliot, Benn, Auden chegara 
ao fim. Um dos poucos poetas-filósofos da segunda metade do século XX, Enzensberger, era antes um caso isolado. E além disso, em todos esses autores eu tendia a confundir o que era ensaísmo e o que era poesia, já que usavam o pensamento como fonte primária de inspiração, e a assim chamada inspiração possuía, neles, algo de intelectual. Em um poeta como Auden chegara a ocorrer que sua linguagem poética fosse mais oratória e teatral, mais endereçada ao público do que sua prosa ensaística, quase sempre muito subjetiva, diarística, fragmentária, quase como se escrita para seu uso pessoal. Além disto, Auden remetia aos clássicos da sátira, da epístola em versos, do poema discursivo e didático, uma espécie de ensaísmo versificado. Era ainda possível fazer algo parecido? Acredito que não. Tanto a tradição da modernidade (Baudelaire) como a tradição clássica (Horácio) havia englobado grandes doses de ensaísmo, mas reconduzir o ensaísmo para a poesia me parecia quase impossível e, na Itália, o caso de Pasolini o demonstrava. Lettere luterane são um poema em prosa mais bem resolvido e mais eficaz do que Trasumanar e organizzar, no qual o uso do verso nada mais é do que uma convenção tipográfica.

\section{III}

Também o romance do século XX se comprometeu muito com o ensaísmo. Proust poderia ser considerado mais um herdeiro de Montaigne do que de Balzac e Flaubert. A prosa de Kafka é construída com a matéria do aforismo e da parábola. Mann e Musil usaram o romance como habitat do pensamento, o que também fez, mais tarde, Milan Kundera, enquanto Calvino, assim como Pasolini, concluiu sua carreira de escritor com excelentes livros de prosa, indeciso entre ensaio e conto: Collezione di sabbia, Lezioni americane, Palomar.

Portanto a modernidade, sobretudo no século XX, reservou uma centralidade estratégica para a forma ensaística. O século da crise dos gêneros não poderia deixar de pedir ajuda ao mais crítico e instável dos gêneros, o gênero literário da reflexão, da interpretação e da autoconsciência.

Apesar da importância da epistemologia e da ontologia, conduzida ao ponto máximo por Popper e Heiddegger, um dos resultados mais característico do pensamento moderno foi o existencialista, aproximando a filosofia da vida individual, da autobiografia, do diário, da literatura. Já em Kierkegaard, tido em geral como o inventor dessa modalidade do filosofar, a autenticidade do pensamento se mede a partir 
da singularidade do existir: sua forma não é mais o tratado sistemático, é o diário. Mas com a filosofia existencial, diarística e autobiográfica, voltamos à forma do ensaio. A tradição ensaística, no Ocidente, foi um ramo pouco conhecido ou subvalorizado da filosofia. Na verdade, nem mesmo a extraordinária (talvez excessiva) fama de Nietzsche fez com que se entendesse que Nietzsche é somente um ensaísta entre muitos e que não somente Montaigne ou Pascal, mas também são filósofos Diderot, Leopardi, Baudelaire, Ruskin. Isto vale também para o pensamento político, sociológico e psicológico, que frequentemente, em seu momento fundador, toma a forma do reportage $e^{2}$, da narração, da descrição a partir do real. A descrição que Tocqueville faz dos Estados Unidos, o reportage de Engels sobre a classe operária inglês, a autobiografia política de Alexander Herzen Passado e Meditações, mas também a descrição freudiana de vários casos clínicos mostram que a forma híbrida e mista do ensaio é particularmente adequada à descoberta de novos campos de pesquisa.

\section{IV}

A partir da metade do século XX ocorreu por fim a sintomática situação vivida pela crítica literária, a qual, como que repentinamente despertada de um sono dogmático secular, decidiu romper com a tradição e se refazer radicalmente, passando assim das névoas do mito e do impressionismo às certezas da ciência. As duas décadas estruturalistas e semiológicas -, época amplamente marcada pelo metodologismo -, levou a pensar que toda a precedente crítica em forma de ensaio deveria ser, de uma vez por todas, superada. A ideia de uma crítica literária como "ciência do texto poético", a própria definição teórica de função poética da linguagem e de literariedade conduziram à separação da linguagem crítica frente à linguagem comum, ao senso comum, ao saber pré-científico. Na realidade, uma longa série de grandes críticos literários do século $\mathrm{XX}$, dotados de extraordinário talento teórico-especulativo, como Spitzer, Sklovski, Benjamin, Auerbach, Edmund Wilson, Adorno não eram totalmente puros cientistas do texto literário: eles eram, antes de mais nada, ensaístas no sentido mais específico do termo. Toda sua produção crítica era uma mescla de vários saberes, inventava categorias teóricas, visava a um público, era politicamente orientada, definia o aqui-e-agora da crítica diante de uma situação social, institucional, comunicativa e 
autobiográfica. Os maiores críticos do século XX mostravam que não era possível depurar e especializar as operações analíticas e interpretativas sem reduzir a fisionomia do próprio objeto-literatura. Este não é somente um conjunto de textos, é a relação dos textos que lemos como textos literários com outros textos, mas também com os autores e suas intenções, com os leitores e suas expectativas. A literatura, em particular a contemporânea, é uma entidade móvel e fugidia. Para aferrá-la, para descrevê-la adequadamente, para ambientá-la no seu contexto, a crítica deve saber inventar uma linguagem adequada, com suas modalidades retóricas e estilísticas. Também a epistemologia tem a sua estilística. E a atividade crítica não é somente ciência e práxis institucional, é um empreendimento individual com riscos incalculáveis, que teoria alguma e método algum poderão jamais garantir ou proteger da falência e do erro.

Portanto, em crítica literária, a forma ensaística não é pura e simplesmente "a bela escrita", longe disto. É a forma que deve fielmente corresponder à práxis real, é peripécia cognitiva através da qual um tipo específico de escritor, o crítico, conhece e constrói seu objeto; ou melhor, evita transformar a obra literária em pura entidade textual higienicamente objetivada e distanciada, sem se contaminar pela sua liberdade e riqueza, seja formal ou semântica.

Mas se a crítica literária é afinal um gênero literário a meio caminho entre a ciência e invenção, se todo crítico é um tipo particular de escritor que trabalha com os produtos de outros escritores, com as metamorfoses da ideia de literatura e daqueles que a usam, então são realmente muitas as coisas a serem ditas sobre ensaístas e sobre críticos.

Para entender melhor as características gerais da forma ensaística, mais do que teorizar é útil estudar de perto "o que fazem" diferentes tipos de ensaístas e, pouco a pouco, "como é feito", como funciona o ensaio. Referi-me ao ensaísmo dos críticos literários. Foi esse, no início dos anos de 1980, meu ponto de partida.

No volumezinho publicado pela Einaudi La ragione critica $(1986)^{3}$, no qual Franco Brioschi falava de historiografia literária e Costanzo Di Girolamo fazia o balanço da pesquisa teórica, propus uma rápida síntese

3 Di Girolamo, C., Berardinelli, A. e Brioschi, F. La ragione critica. Prospettive nello studio della letteratura. Torino: Einaudi, 1986. 
tipológica, que há alguns anos me acompanhava e que, naquele caso, me servia somente para dar uma primeira ideia da variedade do ensaísmo crítico.

Existem críticos que entram nas obras literárias e no sistema-autor como se entra em uma mônada sintetizadora do mundo; críticos literários que se interessam pouco por ideias gerais, desconfiados da historiografia, incapazes de contemplar as épocas literárias por fora e do alto, como se contempla uma paisagem. São pensadores que precisam agarrar um texto ou atravessar um autor para pensar e para iluminar a realidade, para entender alguma coisa sobre a história, sobre o que aconteceu ou está acontecendo aos olhos dos indivíduos e das sociedades humanas. A inteligência desse tipo de críticos almeja a individuação. Mesmo se vez ou outra teorizam (e o fazem frequentemente com grande originalidade) é como se partissem do zero, não de ideias herdadas ou elaboradas em precedência, ou anteriormente à leitura. Não aplicam ideias, teorias ou métodos, antes as retiram de uma profunda convivência e familiaridade com certos autores. A estilística de Spitzer e o formalismo de Sklovski são bastante empíricos, seu gosto pela forma teórica e metodológica nasce no decorrer do processo, em estreito contato com os textos. Teorizam lendo, mais do que lêem apoiando-se em teorias. Da mesma família são também Benjamin (ao quem Adorno, não por acaso, censurava certa fragilidade teórica), Giacomo Debenedetti e Roland Barthes: inteligências às vezes funambulescas mas que entram em ação somente no momento em que aferram o tecido verbal ou perseguem o caso singular de um único autor.

A segunda categoria seria representada por aqueles críticos literários que funcionam como historiadores das ideias, dos temas, das formas: grandes construtores e narradores de acontecimentos culturais a partir dos quais, e somente através destes, os escritores encontram individualmente um sentido e um lugar. Na Itália o modelo deste tipo de crítica é, naturalmente, Francesco De Sanctis, em cuja Storia della letteratura italiana a peripécia dialética das contraposições e dos antagonismos entre os autores, estilos e épocas é quase mais original e ousada que as análises-retrato. No século XX, basta pensar em Auerbach, Edmund Wilson, Frank Raimond Leavis que, como ensaístas, diríamos tender ao gênero épico: eles estudam os modos de representação da realidade, mas a realidade para eles existe, possui sentido e interesse também por si mesma, para além e para aquém da literatura.

Finalmente o ensaísmo crítico dos escritores. Sem dúvida, T.S. Eliot conseguiu criar sua poética pessoal e ao mesmo tempo tornar-se um verdadeiro pontifex maximus, mesmo entre os acadêmicos. Mas em 
geral o grande ensaísmo crítico produzido por escritores (Woolf e Valéry, Forster e Mann, Montale, Auden, Octavio Paz) é, creio que injustamente, descurada pelos estudiosos. Os mais influentes foram os autores com temperamento de líder ou de chefes carismáticos, como Pound, Brecht, Breton. Trata-se, de todo modo, de uma crítica que oscila entre a autobiografia e a pedagogia, entre o gesto idiossincrático, autodefensivo, e o prescritivo, autoritário.

A outra hipótese lançada por mim, não tipológica, mas analítica, era a das três dimensões que definem um poliedro ensaístico: a dimensão teórica, a pragmática e a estilística. Também neste caso, pensava principalmente no ensaísmo dos críticos literários; mas ensaístas de dominante filosófica ou política, ou mesmo narrativa, podem ser considerados e descritos nos mesmos termos.

Trata-se substancialmente de verificar, em um único texto ou autor, que papel desempenham, nas suas relações recíprocas, $a$ ) as idéias, $b$ ) os canais e as formas da comunicação pública, c) os jogos formais, as predileções, as obsessões figurais, o estilo enquanto caracterização individual e estritamente literária. Qual dessas dimensões predomina na estruturação de um texto ensaístico? É claro que, por exemplo, no ensaísmo de autores como Karl Kraus e Orwell a dimensão pragmática, a relação com o público de leitores, a eficácia e a força comunicativa e persuasiva estão continuamente em primeiro plano. Em Adorno, em Sartre, em Ortega, em Gramsci é a paixão pelas idéias e pelos sistemas teóricos que movimenta a escritura: o estilo é modelado pela elaboração do conceito. Nos ensaios de Barthes, Octavio Paz e Calvino o leitor, ao contrário, , não esquece jamais que afirmações e descrições, mesmo que interessantes em si mesmas, chegam a nós pela mediação de um estilo particularmente elaborado que nasce da imaginação literária do escritor.

De qualquer modo, no ensaísmo não nos defrontaremos jamais com uma ficcionalizão fundamental (como no romance o no teatro), nem com a simples, pura e absoluta subjetividade (como na poesia). O ensaísta se atém à realidade. Pode investigá-la através da imaginação, mas não a substitui com pela imaginação. Possui um estilo, mas seu estilo não dita leis para o que quer dizer, nem pode transformá-las radicalmente. Até mesmo nos diários de Kafka, de Kierkegaard, no Zibaldone de Leopardi, nos cadernos de Simone Weil, nos aforismos de Lichtenberg ou de Kraus há algo de didático, de pedagógico (talvez autopedagógico), de 
comunicativo. O leitor nunca entra em um outro mundo, em um mundo paralelo e alternativo ao real, permanece neste mundo, e o que lê deve sempre ser tomado ao pé da letra. O máximo de audácia fantástica no ensaio será, talvez, o paradoxo (de Swift a Pasolini) que institui o impossível para revelar uma realidade de fato.

Não se deve, contudo, acreditar que o estetismo ou literariedade do gênero ensaístico seja algo de inalcançável e insólito. Algo semelhante ocorre na pintura com o gênero do retrato. As grandes obras-primas do gênero, de Rafael a Velásquez, entre outros, são também "invenções a serviço da realidade". O objeto do retrato deve ser reconhecido, talvez para além de si mesmo, em uma verdade de tal modo individual e contingente que seja capaz de transcender a contingência e a individualidade. Com efeito, o retrato é um dos subgêneros mais praticados do ensaísmo . Nos períodos em que a crítica literária observou mais os autores do que os textos, o crítico foi acima de tudo um retratista. Nos últimos anos, na Itália, Cesare Garboli retomou a tradição crítica do retrato elevando-a a níveis de verdadeiro virtuosismo. O retrato permanece como a forma mais comum e praticada pela crítica não acadêmica, movendo-se entre jornalismo e narrativa. Estudiosos tão diferentes entre si como Mario Praz e Norberto Bobbio mostraram o melhor de si no gênero do retrato. Estamos aqui, claramente, na grande e antiga tradição do ensaio, que têm em Teofrasto e Plutarco seus mais longínquos predecessores.

\section{VII}

Uma última consideração. Parece-me que a Europa no século XX teve com o ensaísmo uma ligação privilegiada. Somos hoje o continente menos capaz de inventar e propor mitos e histórias. A literatura européia, mesmo nos últimos dois séculos, produziu extraordinárias obras-primas em poesia e romance. O romance em particular mantevese por longo tempo um gênero literário tipicamente europeu. Mas tenho a impressão que nossa capacidade narrativa esteja se esgotando. É no ensaísmo, no entanto, no gênero literário veículo de interpretações, análises e comentários, que nos últimos cinqüenta anos a Europa mais produziu. Em suma: interpretamos mitos e relatos produzidos alhures, na América, Ásia e África. Meu diagnóstico não pretende ser negativo, mas uma simples constatação. O pensamento crítico, a recusa dos dogmas, as dúvidas sobre nós mesmos e sobre nosso passado histórico, a arte do diálogo e da discussão não são certamente patrimônio exclusivo 
da cultura européia. Advertamos, contudo, que o iluminismo, isto é, a racionalidade capaz de colocar em discussão a si própria, a sua própria lógica e seus próprios fins, faz parte hoje da nossa herança histórica. $\mathrm{O}$ mundo social e material no qual vivemos (economia, tecnologia, sistemas políticos) é de específica responsabilidade da cultura européia. Contribuímos direta ou indiretamente para a transformação de todo o planeta. Trata-se agora de entender melhor o que inventamos e onde nos levarão nossas invenções. Talvez também por isso, o ensaísmo, a forma literária da reflexão, é o nosso mais provável destino literário. 
